\title{
Electronic Cigarettes: Exposure to secondhand vapors at a long-term healthcare company
}

\author{
Nicole Harris ${ }^{1}$, Gordon Lee Gillespie ${ }^{* 2}$, Kermit G. Davis ${ }^{2}$ \\ ${ }^{1}$ University Hospital Medical Center, Cincinnati, OH, United States \\ ${ }^{2}$ University of Cincinnati, Cincinnati, $\mathrm{OH}$, United States
}

Received: September 1, 2020

DOI: $10.5430 /$ jnep.v11n2p1
Accepted: September 24, $2020 \quad$ Online Published: October 15, 2020

URL: https://doi.org/10.5430/jnep.v11n2p1

\begin{abstract}
Introduction: Healthcare workers in long term care settings have limited control over their occupational secondhand exposure to electronic cigarettes and other tobacco products.

Methods: The study aimed to identify the perceived frequency of exposure to exhaled electronic cigarette vapor on healthcare workers within two sites of a long-term healthcare company. An online survey was completed by 149 (out of approximately 500) employees that asked about electronic cigarette personal usage, concerns for exposure, exposure times, and demographic data. Results: Twelve percent of all survey respondents expressed concerns related to second-hand exposure. Of those exposed, employee estimated exposure time was 2.1 minutes per shift for electronic cigarettes compared to 12.1 minutes per shift for cigarettes/cigars/pipes.

Conclusions: Overall self-reported secondhand exposure to electronic cigarettes and cigarettes/cigars/pipes was low. To determine a definitive exposure level, quantitative sampling can be done related to chemical exposure via passive inhalation of the smoke and vapor cloud for cigarettes and electronic cigarettes, respectively. Education can be provided to healthcare workers and residents in long-term care facilities regarding risk of exposure to secondhand smoke to alleviate employees' concerns with exposure.
\end{abstract}

Key Words: Occupational, Vape, Secondhand, Healthcare worker

\section{INTRODUCTION}

The popularity of electronic cigarettes, commonly known as e-cigs, has increased over the last several years. In 2010, $2 \%$ of U.S. adults stated they had used electronic cigarettes; however, by 2014, that number increased by over six times to $12.6 \%$ of U.S. adults. ${ }^{[1]}$ With increasing use and popularity, employers will potentially have to consider the effects of exposure to their employees from the chemicals expelled by people using electronic cigarettes. One such industry is healthcare. In long-term care facilities or assisted living centers, residents 'move in' to the facilities, which becomes their home. Healthcare workers (e.g., nurses, dietary, therapists, aides, etc.) go in and out of the resident's home to care for them and therefore may be occupationally exposed to secondhand vapors if the resident, or the resident's visitors, are actively using electronic cigarettes. Healthcare workers in these settings may have limited control over their occupational secondhand exposure to cigarettes and other tobacco products. In one such facility, the vice president of operations reported a concern for employees' exposure to electronic and other nicotine based product exposure. Therefore, the objective of this study was to assess the perceived

\footnotetext{
*Correspondence: Gordon Lee Gillespie; Email: gordon.gillespie@uc.edu; Address: University of Cincinnati, PO Box 210038, Cincinnati, OH, 45221-0038, United States.
} 
electronic cigarette vapor and tobacco smoke exposures in a sample of healthcare workers in a long-term care facility in southwest Ohio, United States.

\subsection{Background}

An electronic cigarette is a battery powered device, which consists of a tank or cartridge to hold a liquid flavoring/nicotine solution and a heating element. ${ }^{[2]}$ The heating element is used to aerosolize the liquid (there are many different brands and available flavorings for use in electronic cigarette devices, which may or may not contain nicotine), which is then inhaled into the lungs. ${ }^{[2]}$ When the user of the device exhales, a vapor cloud/trail is released into the environment. ${ }^{[3]}$

Although these electronic devices have been available for many years (originally manufactured in 2003), there are limited data on the health effects for users and bystanders. ${ }^{[3]}$ Because of the lack of federal regulations in the United States for electronic cigarettes (as compared with cigarettes), they can be perceived as safe to the public. The lack of regulation surrounding electronic cigarettes subjects the devices and flavorings to mislabeling. For example, liquids labelled as nicotine free, may still contain quantities of nicotine. One brand labeled as containing $0 \mathrm{mg}$ of nicotine, actually was found to have a varying range of $0.07 \mathrm{mg}$ to $21.8 \mathrm{mg}$ of nicotine when tested in a lab. ${ }^{[4]}$ Shober et al. ${ }^{[5]}$ noted during their study of electronic cigarettes, the amount of nicotine in the products tested contained 1.2 times more nicotine than what the manufacturer declared. Additionally, Blank et al. ${ }^{[4]}$ reported that there are over 7,700 liquid flavorings that contain nicotine in amounts of $0 \mathrm{mg} / \mathrm{ml}$ to $36 \mathrm{mg} / \mathrm{ml}$ or higher. Czogala et al. ${ }^{[2]}$ conducted an experimental study, which showed that electronic cigarettes emit significant amounts of nicotine, but the amount emitted was directly related to the brand of electronic cigarette being used.

The marketing for electronic cigarette devices (such as reporting to be nicotine free) leads people to believe they are choosing a 'healthy alternative' rather than smoking cigarettes, cigars, or pipes. However, Tan, Mello, Sanders, Jackson, and Bigman ${ }^{[6]}$ found adult participants were not aware of the chemicals in electronic cigarettes and thus did not know they contained potentially dangerous chemicals. The message being delivered via different marketing strategies is that electronic cigarettes are healthier, cheaper, can be used indoors or outdoors, cleaner, more modern, and emit a "harmless water vapor". ${ }^{7]}$ As of early 2019, electronic cigarettes were still being marketed as a safer alternative to smoking tobacco cigarettes and as a smoking cessation tool. ${ }^{[3]}$ Yet, the perception of risk for persons exposed to secondhand electronic cigarettes is still unknown.
Additionally, electronic cigarettes contain many potentially toxic chemicals, several of which are known carcinogens, including: carbonyls, formaldehyde, acetaldehyde, propylene glycol, and acrolein. ${ }^{[2]}$ During an experimental study, Czogala et al. ${ }^{[2]}$ compared indoor air quality on days when electronic cigarettes were and were not being used. The researchers found that varying brands of electronic cigarette liquids can produce and emit different substances in varying quantities. $^{[2]}$ Fine and ultrafine particles were found to be released into the air, which can then be inhaled and deposited in the lungs. ${ }^{[2]}$ In that same study, Czogala et al. ${ }^{[2]}$ found that on days where vaping was occurring, there was a $20 \%$ increase in polycyclic aromatic hydrocarbons measured in the air as compared to the control day. Employees smelling the electronic cigarette aroma may have a measureable exposure to byproducts of electronic cigarette smoking. Research is needed to determine exposure to electronic cigarettes as well as perceived risk when exposure occurs. Findings from this research could contribute to organizational policy and employee education related to smoking behavior, both traditional cigarette/cigar/pipe and use of electronic cigarettes.

\section{MethodS}

\subsection{Study design}

A cross sectional design was conducted at two sites of a long-term healthcare company. The study protocol was reviewed by the University of Cincinnati Institutional Review Board and deemed non-human subjects research due to the focus on employee improvement. In addition, the survey and study procedures were reviewed and approved by site administration prior to study initiation. Participants were aware that their participation in the survey was voluntary and anonymous.

\subsection{Sample \& setting}

The setting was two long-term care facilities for older adults (both facilities within one healthcare company) located in southwest Ohio, United States. There were approximately 500 employees between two campuses. All full and part time employees were eligible. Occupational groups were not limited and varied (e.g., clinical/patient services, support services [e.g., dietary, physical therapy], and administration [e.g., billing, information technology]).

\subsection{Online survey}

The survey was designed to ascertain the level of occupational exposure to electronic cigarettes vs. other tobacco containing products (cigarettes, cigars, pipes) and what specific brands of electronic cigarette devices and flavorings were being used. The survey was assessed for face validity by industrial hygienists and researchers with background 
experience in occupational safety and health. Questions inquired about the following:

- Frequency of use by the employees and residents at the two facilities

- Specific types of electronic cigarettes being used

- Employee perceived exposure time (in minutes) to electronic cigarette vapors

- Employee perceived exposure time (in minutes) to other nicotine delivery devices such as cigarettes, pipes and cigars.

The survey (Appendix) included two binary (yes/no) items on personal and/or secondary use of nicotine/electronic cigarette products. For a yes response, open-ended questions solicited additional exposure information: brands/flavorings or how many times per shift a person smoked/was exposed to smoke of nicotine or electronic cigarettes and length of exposures in minutes. Demographic questions focused on number of hours worked per day, job title, race/ethnicity, and age.

\subsection{Procedures}

An electronic survey link was distributed to a convenience sample of all employees $(n=500)$ of both campuses via employee email address by an employee at the project site. Paper copies also were made available for employees who might have chosen to not respond electronically. Responses (electronic and paper) were collected anonymously. Electronic responses were directly entered into a database by respondents via a confidential survey link. Paper responses were entered into a database manually by a member of the project team.

\subsection{Data analysis}

Frequencies and percentages were calculated to report binary exposure data. Averages were calculated for time exposed to cigarette smoke and electronic cigarette vapor. Open-ended questions aimed at soliciting the type and brand of electronic cigarettes. Type and brand of flavorings did not receive a high response rate $(\mathrm{n}=1)$ and therefore were not further analyzed in this paper. Demographic data such as age, years worked in healthcare, hours worked per week, and hours worked per shift are described using means, ranges, and standard deviations.

\section{Results}

\subsection{Demographic characteristics}

A total of 149 (29.8\%) employees participated in the study; however, not all respondents completed all questions. Of the respondents, $110(82 \%)$ were female and $24(18 \%)$ were male. The majority (75\%) of respondents were white/caucasian and non Hispanic or Latino (88\%). Table 1 reports demographic data, which includes frequencies and standard deviations of data where applicable. The mean age of respondents was $48.5 \pm 12.5$ years old, time worked in healthcare was $15.8 \pm 12.8$ years, hours worked per week was $39.3 \pm 8.4$, and number of hours worked per day was $9.6 \pm 6.8$.

Table 1. Summary of demographic data for the study respondents $(\mathrm{N}=135)$

\begin{tabular}{|c|c|c|c|c|}
\hline Characteristic & $\mathbf{N}$ & $\%$ & Mean (sd) & Range \\
\hline Age & & & $48.5(12.5)$ & $20-79$ \\
\hline Experience & & & $17.8(11.9)$ & $<1-50$ \\
\hline \multicolumn{5}{|l|}{ Hours Worked } \\
\hline Per Shift & & & $9.6(8.4)$ & $3-14$ \\
\hline Per Week & & & $39.3(8.4)$ & $15-70$ \\
\hline Female & 110 & 82.1 & & \\
\hline \multicolumn{5}{|l|}{ Race } \\
\hline White & 112 & 83.0 & & \\
\hline Racial minority & 23 & 17.0 & & \\
\hline Hispanic Ethnicity & 2 & 1.5 & & \\
\hline \multicolumn{5}{|l|}{ Shift Length } \\
\hline Full-Time & 118 & 89.4 & & \\
\hline Part-Time & 11 & 8.3 & & \\
\hline Other & 3 & 2.3 & & \\
\hline \multicolumn{5}{|l|}{ Job Role } \\
\hline \multicolumn{5}{|l|}{ Clinical Care } \\
\hline Nursing & 31 & 23.7 & & \\
\hline Allied Health & 24 & 18.3 & & \\
\hline Other & 4 & 3.1 & & \\
\hline \multicolumn{5}{|l|}{ Resident Support } \\
\hline Activities & 13 & 9.9 & & \\
\hline Housekeeping & 12 & 9.2 & & \\
\hline Security & 9 & 6.9 & & \\
\hline Other & 5 & 3.8 & & \\
\hline \multicolumn{5}{|c|}{ Administrative Support } \\
\hline Management Team & 11 & 8.4 & & \\
\hline Billing & 5 & 3.8 & & \\
\hline Other & 17 & 13.0 & & \\
\hline
\end{tabular}

\subsection{Secondhand exposure}

Several questions were asked in regards to secondhand exposure; however, two of the questions served as screening questions. The first screening question set to determine how many employees reported using electronic cigarettes themselves; only one person reported yes. The second screening question was: Do you encounter secondhand smoke from co-workers or residents during your shift? Most $(\mathrm{n}=111$, $75.5 \%$ ) reported they did not encounter any type of passive exposure during their shift. However, $24.5 \%(\mathrm{n}=36)$ reported an exposure to cigarettes/cigars/pipes and $6.8 \%$ (n $=10$ ) an exposure to electronic cigarettes. Of these respondents, 8 (22.2\%) were housekeepers. All 10 of the employees who reported a positive exposure from electronic cigarettes also reported exposure to cigarettes/cigars/pipes. No em- 
ployees reported exposure to electronic cigarettes alone. Of these 10 employees who reported exposure to both electronic cigarettes and cigaretes/cigars/pipes, eight had the job title of housekeeper $(n=5)$, nurse $(n=2)$, payroll $(n=1)$, or supervisor $(n=1)$. The remaining two did not answer the question related to job title. See Table 2 for a summary on exposure findings.

Table 2. Frequency and percentage for exposure to secondhand smoke and vapor and whether a concern existed about exposure $(\mathrm{N}=147)$

\begin{tabular}{ll}
\hline Exposure Data & N (\%) \\
\hline Current secondhand smoke from coworkers or residents & \\
Yes, cigarettes/cigars/pipes & $36(24.5)$ \\
Yes, electronic cigarettes & $10(6.8)$ \\
No & $111(75.5)$ \\
Concerned about secondhand exposure & $29(19.7)$ \\
Yes & $18(62.1)$ \\
No & $11(37.9)$ \\
\hline *For the question, "Do you enocounter secondhand smoke from coworkers or residents \\
during your shift," the percentages exceed 100 due to 10 respondents answering yes for \\
both exposure to cigarettes, cigars, pipes and electronic cigarettes.
\end{tabular}

The following questions were only to be answered if a respondent $(n=36)$ said yes to the question for exposure either from cigarettes/cigars/pipes or electronic cigarettes. The first was to gauge the level of concern the employees were feeling regarding the exposure. Eighteen (50\%) employees indicated they posessed some level of concern related to secondhand exposure.

Twenty-seven employees answered the following question: "How many times do you enter a room per shift that has been smoked in?" Results varied, with $40.7 \%(n=11)$ of these respondents indicating 0 as their answer or wrote in "nonsmoking facility", $14.8 \%(n=4)$ indicating once per shift, $11.1 \%(\mathrm{n}=3)$ indicating twice per shift, and one person stating three times per shift, $3.7 \%(\mathrm{n}=1)$. Additionally, other qualitative comments were provided such as: "not in room but comes from vents", "on average, about one a week", "Outside of offices... or from cars in all parking lots," "not in a room, but it is noticeable when an employee has been smoking," "outside," "not sure," and "guest will often smoke outside the entrance and the smoke enters the building."

Of the 27 employees who responded to "How many times do you enter a room per shift and see someone actively smoking?", $51.9 \%(n=14)$ of respondents reported "0" or "never" as the amount of times per shift they see active smoking occurring in residents' rooms. In comparison, 37\% $(\mathrm{n}=$ 10) of the respondents answered " 0 ", "never", or "none" as the amount of times they enter a room where electronic cigarettes are actively being used. A few $(n=5,18.6 \%)$ respondents answered " 1 " as the number of times they entered a room per shift to see someone actively smoking electronic cigarettes. Two $(7.4 \%)$ participants reported entering a room where cigarettes/cigars/pipes were being used each shift. In relation to electronic cigarettes, one person wrote "outside area, maybe 4" in regard to active exposure and one person answered "1 time/month."

Survey respondents answered two questions about smoking habits in communal areas of the facility grounds as compared to resident rooms. For cigarettes/cigars/pipes, responses ranged from 0 to $10: 12.9 \%(n=4)$ said $0,9.7 \%(n=3)$ said $1,6.5 \%(\mathrm{n}=2)$ reported $2,9.7 \%(\mathrm{n}=3)$ said 3 , and $16.1 \%(\mathrm{n}$ $=5)$ quantified 4 or more times. Additionally, $48.3 \%(n=15)$ wrote in comments including "often", "several", "in designated smoking area", "outdoors frequent, not indoor", "only when I am on break," and "in parking lot." Subsequently, 17 of 31 employees also commented on the frequency of witnessing electronic cigarette usage in communal areas of the grounds per shift: 5 (16\%) employees indicated none, $3(9.7 \%)$ employees indicated once, 7 (23.6\%) employees reported "a few times a day" or "seldom", and $2(6.5 \%)$ employees reported more than 4 times per day. For the employees who reported observing someone smoking in the communal areas, 31 employees provided a response about being close enough to smell it. While $22.6 \%(n=7)$ reported they were not close enough to smell the product, $77.4 \%$ ( $\mathrm{n}=$ 24) said they were close enough to smell the passive smoke or vapor.

The mean time that respondents $(n=30)$ reported being exposed to electronic cigarettes was 2.1 minutes per shift (range: 0-5 minutes/shift) compared to 12.1 minutes per shift (range: 0-120 minutes/shift) for cigarettes, cigars, or pipes.

\section{Discussion}

The purpose of this study was twofold. The primary objective was to assess the perceived electronic cigarette and tobacco smoke exposure in a sample of healthcare workers in two locations of a long-term healthcare company. The secondary objective was to identify the specific brands of electronic cigarettes and flavorings being used to profile the chemical exposures as a component of an occupational risk assessment. Based on the results of the survey, the secondary objective could not be completed due to only one employee reporting self-usage of electronic cigarettes.

In relation to the primary objective, the majority $(75.5 \%)$ of survey participants did not experience exposure to secondhand vapor or regular smoking from co-workers or residents while on the job. This finding is consistent with Rydz, Arrandale, and Peters who found a prevalence of $25 \%$ of healthcare 
workers were believed to have been exposed to secondhand smoke. ${ }^{[8]}$ Moreover, the current study's findings did not reveal a large amount of secondhand exposure from electronic cigarettes within residents' rooms. The prevalence of daily use of electronic cigarettes in older adults is less than $1 \%,{ }^{[9,10]}$ which can account for the relatively low exposure in our study sample.

Interestingly, the greatest frequency for exposure was with housekeepers. This finding could indidate that older adults and family members may avoid using nicotone products in front of healthcare workers (e.g., nurses) due to past education on the importance of quitting use of nicotine containing products. People may be more likely to ignore the presence of housekeepers, accounting for the higher prevalence of exposures in housekeeping staff.

A follow-up survey was deployed over a two-day period to clarify some of the equivocal responses to the first study and to obtain additional information. A total of 38 of the 500 employees completed the second survey. This was a separate anonymous survey so the participants may or may not have completed both surveys.

When asked about entering residents' rooms who had recently been smoking, 8 employees had observed active electronic cigarette use in resident rooms and 16 in communal areas. For cigarettes/cigars/pipes, 14 employees had observed this use in resident rooms and 3 in communal areas. These findings were surprising given the organization had a smoke-free campus policy. It is possible the true prevalence of smoking is higher than reported, but residents terminate their use due to previous sanctions when use was witnessed. A controversy could exist over the use of these products. While use in a communal space should continue to be prohibited to prevent secondhand exposures to others, use in a private room is harder to monitor. Fortunately, use of electronic cigarette and other tobacco products is much lower than the national average ${ }^{[11]}$ which helps to reduce secondhand exposures to employees. Exposures, while infrequent, exist. Even in occupational settings with a smoke-free workplace policy, there is a significantly increased odds for experiencing a workplace injury when exposed to secondhand smoke. ${ }^{[12]}$ It is important that behavioral interventions be implemented to reduce residents' use of tobacco products. Ongoing surveillance can aide in identifying specific toxins present in electronic cigarettes being used by residents.

\subsection{Limitations}

There are a few considerations when interpreting the current results. First, the response rate was relatively low with 149 employees out of 500 (29.8\%) completing the survey.
Given the increased negative focus on the use of electronic cigarettes, users may have opted to not participate due to concerns for being perceived negatively. Some employees may have worried about company retaliation even though the research team conducted the study anonymously. Employee job roles on the first survey were not differentiated, which could have impacted the reporting rate. However, with nearly $30 \%$ of employees responding, this limitation was minimized.

Second, the survey results were generated from self-reported data. Follow-up studies with direct observation and other objective quantification can be undertaken to measure the actual use, frequency, and chemical exposure from electronic cigarettes. Additionally, employees may have actual exposure to electronic cigarettes, but not realize it, thus reporting no exposure. While outside the scope of this study, a consideration for a future onsite study is to obtain quantitative exposure measurements via personal air and environmental sampling. Environmental sampling also would determine how far the vapor clouds travel once exhaled, as several employees reported being close enough to smell the products being exhaled or reported they could smell vapors traveling through the air ducts of the facility.

Third, results from both surveys (the original and the follow up) indicate that the communal areas of the grounds had higher observations of electronic cigarette usage. Only one employee reported personally using electronic cigarettes; however, it is reasonable to believe that number is actually higher.

Lastly, the additional occupational safety and health concerns related to the use of electronic cigarettes were not explored in this study. For example, electronic cigarettes pose a fire hazard in addition to emitting chemicals. The devices have a potential for fire and explosions to occur due to overheating of the battery mechanism within the electronic cigarette device ${ }^{[7]}$ In order to understand the true risk for electronic cigarettes, these concerns need to account for all exposures and risks.

\subsection{Implications for occupational health practice}

Exposure to secondhand smoke was greatest among housekeeping staff. While housekeeping staff are not clinicians, they interact regularly with residents of long term care settings and are likely to have a trusted interpersonal relationship. Housekeeping staff can be trained to communicate with residents about their desire to terminate use of nicotine containing products. Occupational health nurses can leverage these relationships to become an extension of the clinical care team such that residents seek smoking cessation 
counseling from long term care nurses and other providers.

Participants expressed their concerns for exposure to secondhand smoke. It is important for occupational health nurses to develop and implement educational programs for long term care workers and residents describing risk for secondhand smoke from electronic cigarettes and cigarettes/cigars/pipes. Fortunately, rates of second-hand smoke in healthcare and blue collar workers have shown a downward decline based on National Health and Nutrition Examination Survey (NHANES) findings in the United States. ${ }^{[13]}$ However, rates for exposure to electronic cigarettes are likely to be increasing. To further address these concerns, occupational health nurses can monitor actual exposure and debrief exposure findings with employees. If exposure is deemed excessive, a mitigation plan can be developed to minimize exposure. Alternatively, housekeeping staff and other frequently exposed employees can rotate to a particular resident's room so that weekly exposure is reduced.

\section{Conclusion}

Occupational related exposure to electronic cigarette usage was found to be relatively low among the two sites of a long-term healthcare company. The majority $(75 \%)$ of survey respondents did not report any secondhand exposure to electronic cigarettes or cigarettes/cigars/pipes. Frequency and duration of exposure were more prevalent in relation to cigarettes/cigars/pipes compared to electronic cigarettes. To determine a definitive exposure level, quantitative sampling can be done related to chemical exposure via passive inhalation of the smoke and vapor cloud for cigarettes and electronic cigarettes, respectively.

\section{ACKNOWLEDGEMENTS}

This work was supported by the National Institute for Occupational Safety and Health through the Targeted Research Training program of the University of Cincinnati Education and Research Center, grant T42OH008432. We would like to thank Nicholas Grisso, Nell Wickstrom, and Yao Addor for their assistance with survey development, collection, and analysis of both surveys discussed.

\section{CONFlicts OF INTEREST Disclosure}

The authors declare that they have no competing interests.

\section{REFERENCES}

[1] Kruse G, Kalkhoran S, Rigotti N. Use of electronic cigarettes among U.S. adults with medical comorbidities. Am J Preventive Med. 2017; 52(6): 798-804. PMid:28108191 https://doi.org/10.1016/j . amepre.2016.12.004

[2] Czogala J, Goniewicz ML, Fidelus B, et al. Secondhand exposure to vapors from electronic cigarettes. Nicotine \& Tobacco Research 2014; 16(6): 655-662. PMid:24336346 https://doi.org/10.1 $093 /$ ntr/ntt203

[3] Ioakeimidis N, Vlachopoulos C, Tousulis D. Efficacy and safety of electronic cigarettes for smoking cessation: a critical approach. Hellenic J Cardiology. 2016; 57(1): 1-6. https ://doi.org/10.101 6/S1109-9666(16)30011-2

[4] Blank MD, Breland AB, Cobb CO, et al. Clinical laboratory evaluation of electronic cigarettes/electronic nicotine delivery systems: Methodological challenges. Tobacco Regulatory Science. 2016; 2(4): 426-439. PMid:28819633 https://doi.org/10.18001/TRS.2 .4 .12

[5] Schober W, Szendrei K, Matzen W, et al. Use of electronic cigarettes (e-cigarettes) impairs indoor air quality and increases FeNO levels of e-cigarette consumers. International J Hygiene Environmental Health 2014; 217(6): 628-637. PMid:24373737 https ://doi.org/10.1 016/j.ijheh.2013.11.003

[6] Tan AS, Mello S, Sanders-Jackson A, et al. Knowledge about chemicals in e-cigarette secondhand vapor and perceived harms of exposure among a national sample of U.S. adults. Risk Analysis. 2017; 37: 1170-1180. PMid:27595498 https://doi.org/10.1111/ri sa. 12676
[7] Grana R, Benowitz N, Glantz SA. E-cigarettes: A scientific review. Circulation. 2014; 129(19): 1972-1986. PMid:24821826 https : //doi.org/10.1161/CIRCULATIONAHA.114.007667

[8] Rydz E, Arrandale VH, Peters CE. Population level estimates of workplace exposure to secondhand smoke in Canada. Canadian J Pub Health. 2020; 111: 125-133. PMid:31489599 https ://doi .org/ 10.17269/s41997-019-00252-x

[9] Bao W, Liu B, Du Y, et al. Electronic cigarette use among young, middle-aged, and older adults in the United States in 2017 and 2018. JAMA Int Med. 2020; 180(2): 313-314. PMid:31609399 https : //doi.org/10.1001/jamainternmed.2019.4957

[10] Oakly A, Edwards R, Martin G. Prevalence of e-cigarette use from a nationally representative sample in New Zealand. Addictive Behaviors. 2019; 98: 1-6. PMid:31233951 https ://doi.org/10.1016/ j.addbeh.2019.06.013

[11] Smoking and tobacco use: cigarette smoking among adults in the United States [Internet]. Atlanta, GA: Centers for Disease Control and Prevention; 2019. [cited 2020, Sep 1]. Available from: https://www.cdc.gov/tobacco/data_statistics/fa ct_sheets/adult_data/cig_smoking/index.htm

[12] Lee W, Lee S, Kim J, et al. Relationship between exposure to secondhand smoke in the workplace and occupational injury in the Republic of Korea. Ann Work Exposures Health. 2018; 62(1): 41-52. PMid:29267948 https://doi.org/10.1093/annweh/wxx089

[13] Wei B, Bernert JT, Blount BC, et al. Temporal trends of secondhand smoke exposure: Nonsmoking workers in the United States (NHANES 2001-2010). Environ Health Perspect. 2016; 124: 15681574. PMid:27164619 https ://doi .org/10.1289/EHP165 